\title{
Translocation of $\mathrm{H}$-Ras and its implications in the development of diabetic retinopathy
}

\author{
Renu A. Kowluru* and Mamta Kanwar \\ Department of Ophthalmology, Kresge Eye Institute, Wayne State University
}

\begin{abstract}
H-Ras, a small molecular weight G- protein, undergoes post-translational modifications enabling its translocation from cytosol to the membrane. Hyperglycemia increases apoptosis of retinal capillary cells via activation of $\mathrm{H}$-Ras, which can be ameliorated by farnesylation inhibitors. Our aim is to investigate the mechanism of retinal H-Ras activation in diabetes. H-Ras and Raf-1 were quantified in the retinal membrane and cytosol fractions obtained from streptozotocin-induced diabetes rats, and the role of post-translation modification was determined by investigating the effect of simvastatin on diabetes-induced alterations. The effect of $\mathrm{H}$-Ras-siRNA on membrane translocation and apoptosis was also determined in bovine retinal endothelial cells (BRECs). Diabetes increased expressions of H-Ras and Raf-1 in the retinal membranes, and simvastatin prevented such translocation. Glucose-exposure of BRECs increased membrane H-Ras expression and H-RassiRNA prevented this translocation, and also decreased their apoptosis. Thus membrane translocation of H-Ras is a plausible mechanism responsible for accelerated apoptosis of retinal capillary cells in diabetes.
\end{abstract}

\section{INTRODUCTION}

Hyperglycemia is considered as the major initiating factor in the development of diabetic retinopathy. Many hyperglycemia-initiated metabolic abnormalities have been implicated in the development of diabetic retinopathy, however, the exact mechanism responsible remains elusive.

H-Ras, a member of small molecular weight GTPases, cycles between a guanosine triphosphate-bound active and a guanosine diphosphate-bound inactive state [1]. It acts as a "molecular switch," converting signals from cell membrane to the nucleus [2]. Posttranslational modification of H-Ras activates it by increasing its hydrophobicity and translocating it from cytosol to the membrane [3]. Our studies have shown that H-Ras activation is one of the important steps involved in the apoptosis of retinal endothelial cells and ultimately in the development of diabetic retinopathy, and farnesylation inhibitors inhibit glucose-induced apoptosis of retinal capillary cells [4,5]. Further, H-Ras mediated apoptosis of retinal capillary cells is via its key effector protein, Raf-1, which is predominantly cytosolic [4,5]. Others have shown that the activation of Ras promotes translocation of Raf- 1 to the plasma membrane [6,

(C) 2009 Elsevier Inc. All rights reserved.

*Address correspondence to: Renu A. Kowluru, Ph.D., Kresge Eye Institute, 4717 St. Antoine, Detroit, MI 48201, Tel: 313-993-6714, Fax: 313-577-8884, E-Mail: rkowluru@med.wayne.edu.

Publisher's Disclaimer: This is a PDF file of an unedited manuscript that has been accepted for publication. As a service to our customers we are providing this early version of the manuscript. The manuscript will undergo copyediting, typesetting, and review of the resulting proof before it is published in its final citable form. Please note that during the production process errors may be discovered which could affect the content, and all legal disclaimers that apply to the journal pertain. 
7]. However, how diabetes affects the subcellular translocation of H-Ras in the retina is not explored.

In this study we have investigated the mechanism of H-Ras activation in diabetes. The quantitative measurements of the expression of H-Ras and Raf-1 were made in the retinal membrane of diabetic rats. Simvastatin is shown to block membrane translocation of H-Ras via Ras farnesylation-associated mechanism [8], the effect of administration of simvastatin on diabetes-induced membrane translocation of H-Ras was also investigated. Since retinal capillary cells are the target of histopathology associated with diabetic retinopathy, the effect of H-Ras-siRNA on glucose-induced membrane translocation and apoptosis was determined in isolated retinal endothelial cells.

\section{METHODS}

\section{Rats}

Wistar rats (200-220g, male) were made diabetic by streptozotocin ( $55 \mathrm{mg} / \mathrm{kg} \mathrm{BW})$, and insulin was administered to diabetic rats to allow slow weight gain while maintaining hyperglycemia (blood glucose 20-25mM). Age-matched normal rats served as control. A group of diabetic rats received powder diet (Purina 5001) supplemented with $10 \mathrm{mg} / \mathrm{kg} /$ day simvastatin (Merck Research Laboratories), and this was initiated soon after establishment of diabetes. Each group had 10-12 rats, and the entire colony of rats (normal, diabetic and diabetic with simvastatin diet) received fresh powder diet weekly. The rats were euthanized by overdose of pentobarbital at 2 months of diabetes, and the retina was removed immediately and used for biochemical measurements. Glycated hemoglobin values (normal $=5-6 \%$, diabetes or diabetes +simvastatin $=11-12 \%$ ) measured $2-3$ days before termination of the experiments using affinity columns (kit 442-B, Sigma Chemicals), showed that simvastatin had no effect on the severity of hyperglycemia. Treatment of the animals conformed to the National Institute of Health Principals of Laboratory Animal Care, the Association for Research in Vision and Ophthalmology Resolution on the Use of Animals in Research.

\section{Retinal endothelial cells}

Bovine retinal endothelial cells (BRECs) were grown in medium containing heat inactivated fetal bovine serum and endothelial cell growth supplement [4,5]. Confluent cells from $3^{\text {rd }}$ to $6^{\text {th }}$ passage were incubated in normal $(5 \mathrm{mM})$ or high $(20 \mathrm{mM})$ glucose for 4 days. Control incubations containing $20 \mathrm{mM}$ mannitol always were run simultaneously to rule out the effect of increased osmolarity. All cells received fresh media every 48 hours, and each experiment was repeated with 3-4 different cell preparations.

\section{Transfection of endothelial cells}

BRECs from $3^{\text {rd }}$ to $5^{\text {th }}$ passage were transfected with H-Ras small interfering RNA (H-RassiRNA) using transfection reagents and siRNA duplex from Santa Cruz Biotechnology, CA. The transfection complex was prepared by adding H-Ras siRNA and siRNA transfection reagent. The mixture was incubated for 30 minutes at room temperature. The cells were washed and overlayed with the transfection complex, and incubated for 8 hours at $37^{\circ} \mathrm{C}$. Parallel incubations were carried out using non-targeting scrambled siRNA, and also the transfection reagent alone (Mock). After the transfection, the media was replaced with the $5 \mathrm{mM}$ or $20 \mathrm{mM}$ glucose media and the cells were incubated for 4 days. The cells were rinsed with phosphate buffered saline (PBS), trypsinized, and homogenized as given below. 


\section{Cytosol and heavy membrane fractions}

Heavy membranes were prepared by homogenizing retina or cells in $5 \mathrm{mM}$ HEPES buffer ( $\mathrm{pH}$ 7.4) containing $250 \mathrm{mM}$ mannitol, $70 \mathrm{mM}$ sucrose, $1 \mathrm{mM}$ EGTA, $1 \mathrm{mM}$ DTT and $10 \mu \mathrm{g} / \mathrm{ml}$ each of leupeptin and aprotinin. The homogenate was centrifuged at $200 \mathrm{~g}$ x 2 minutes to remove cell debris, followed by centrifugation at 100,000g x 90 minutes. The pellet was suspended in homogenization buffer and used as heavy membrane, and the supernatant as cytosol fraction.

\section{Activation of H-Ras}

The relative abundance of active Ras was quantified using a Raf-1 binding assay kit (Cytoskeleton, Denver, CO). Retinal homogenate was added to Raf-1RBD, and the Raf-RBD/ GTP-Ras complex was pulled down by glutathione affinity beads. The amount of activated HRas was determined by western blot using H-Ras-Pan specific antibody [5].

\section{Western blot analysis}

Proteins $(20-30 \mu \mathrm{g})$ were subjected to $12 \%$ SDS-PAGE and transferred to nitrocellulose membrane. Immunodetection was performed using antibodies against H-Ras and Raf-1 (Santa Cruz Biotechnology). Membranes were re-probed with $\beta$-actin to evaluate the lane loading. Band intensities were quantified using Un-Scan-It gel digitizing software (Silk Scientific Inc., UT).

\section{RNA isolation and quantification}

Total RNA was isolated using TRIZol reagent (Invitrogen, Carlsbad, CA), as routinely used in our laboratory [9]. RNA was converted to single stranded cDNA using the High Capacity cDNA Reverse Transcription Kit with RNase inhibitor (Applied Biosystems, ABI, CA). cDNA was synthesized using the GeneAmp PCR system 9700 thermal cycler (ABI), and quantified spectrophotometerically.

Quantitative RT-PCR was performed in the retina with 50ng cDNA template using the ABI-7500 sequence detection system, and $\beta$-2-microglobulin (B2M) was used as a housekeeping control. Each sample was measured in triplicate. Genebank accession numbers of Taqman custom PCR primers used for H-Ras and B2M are XM_001061671.1 and NM_012512.1 respectively. The standard PCR conditions included 2 minutes at $50^{\circ} \mathrm{C}$ and 10 min at $95^{\circ} \mathrm{C}$ followed by 40 cycles of extension at $95^{\circ} \mathrm{C}$ for 15 seconds and one minute at $60^{\circ}$ C. Threshold lines were automatically adjusted to intersect amplification lines in the linear portion of the amplification curves and cycle to threshold $(\mathrm{Ct})$ were recorded automatically. Replicated data were normalized with B2M mRNA.

Semi quantitative PCR was performed in BRECs using Gene Amp PCR System 9700 (ABI) for PCR amplification. The forward and reverse primers for H-Ras were: 5'-CCC ACC CTG CCC AAG AG-3' and 5'-TTG ACG TGG TTG ATA GCA AAC AC-3' respectively. Equal volumes of reaction mixture from each sample were loaded onto $1.2 \%$ agarose gels. The images were digitally captured for analysis of intensity with Un-Scan-It software. Levels of the target gene mRNA was normalized relative to $\beta$-actin in the same sample.

\section{NF-kB activation}

NF- $k \mathrm{~B}$ activation was determined by ELISA that is based on the principle that only the active form of NF- $k$ B binds to oligonucleotide containing NF- $k$ B consensus site (5,GGGACTTTCC-3'). The standard concentrations used in the ELISA ranged from $8 \mathrm{pg} / \mu 1$ to $125 \mathrm{pg} / \mu 1[10]$. 


\section{Nitrite levels}

Nitrite (NO) levels were quantified by Greiss reagent as routinely measured in our laboratory using sodium nitrite as a standard [4,11].

Cell death

Cell death was determined by ELISA using Cell Death Detection ELISA ${ }^{\text {PLUS }}$ (Roche

Diagnostics) [12], and was confirmed by measuring the activity of caspase-3 [13].

\section{Statistical analysis}

Data are reported as mean $\pm \mathrm{SD}$ and experimental groups were compared using the nonparametric Kruskal-Wallis test followed by Mann-Whitney test for multiple group comparison. Similar conclusions were also reached by using ANOVA with Fisher or Tukey.

\section{RESULTS}

\section{Effect of diabetes on membrane translocation of H-Ras}

The ratio of H-Ras protein expression in membrane to cytosol fractions was increased from 0.5 in normal rat retina to 1.2 in diabetic rat retina (Figure 1a). In the same diabetic rats the gene expression of $\mathrm{H}-\mathrm{R}$ as in the retinal membranes was 1.7 fold higher compared to normal rats (Figure 1b), and H-Ras was activated by about $40 \%$, as determined by its binding to Raf- 1 (Figure 1c).

As shown in figure 1d, the expression of Raf-1 was significantly increased in the membrane fraction in diabetic rats compared to normal rats; the ratio expression of Raf- 1 expression in membrane to cytosol was 0.7 in normal rat retina and 1.2 in diabetic rat retina.

\section{Effect of simvastatin on H-Ras activation}

Administration of simvastatin ameliorated diabetes-induced increases in H-Ras and Raf-1 membrane expression (Figure 1); the values obtained from simvastatin-treated diabetic rats were significantly different from diabetic rats without simvastatin $(p>0.5)$. This was accompanied by inhibition of retinal H-Ras activation by simvastatin (Figure 1c).

As shown in figure $2 \mathrm{a}$, simvastatin inhibited diabetes-induced activation of retinal NF- $k \mathrm{~B}$ and decreased NO levels, and the values obtained from simvastatin-treated diabetic rats were lower compared to diabetic rats without any supplementation (Figure $2 b ; \mathrm{p}<0.05$ ).

\section{Membrane expression of $\mathrm{H}-\mathrm{Ras}$ in retinal endothelial cells}

Membranes obtained from BRECs incubated in high glucose presented significant increases in the protein expression of H-Ras compared to the cells incubated in normal glucose (Figure 3a). Glucose-induced increase in protein expression of H-Ras was accompanied by increased gene expression; mRNA levels of H-Ras and Raf- 1 were 1.5-1.7 fold higher in the membranes from cells exposed to high glucose compared to normal glucose (Figure $3 \mathrm{~b} \& \mathrm{c}$ ).

In the same cell preparations, as expected, the levels of $\mathrm{NO}$ were increased by $70 \%$ (Figure $4 \mathrm{a}$ ), and their apoptosis by $75 \%$ (Figure $4 \mathrm{~b}$ ) and caspase- 3 activity by $60 \%$ (Figure $4 \mathrm{c}$ ) compared to the cells incubated in normal glucose.

\section{Regulation of $\mathrm{H}-\mathrm{Ras}$ by its siRNA}

Transfection of BRECs with H-Ras-siRNA abrogated glucose-induced membrane translocation of H-Ras and Raf-1. The gene expression of H-Ras in the membrane fraction of cells incubated in high glucose was significantly lower in the H-Ras-siRNA transfected cells 
compared to the mock cells, and the values were similar to those obtained from cells incubated in normal glucose (Figure 3b). In the same cells, H-Ras-siRNA ameliorated glucose-induced membrane translocation of Raf-1 (Figure 3c), and prevented increase in NO levels, apoptosis and activation of caspase- 3 activity (Figure 4). In contrast, when the cells expressing scrambled siRNA were incubated in high glucose, the values were significantly higher compared to those obtained from mock cells or scrambled siRNA cells incubated in normal glucose. However, due to sample availability, H-Ras activation assay and protein expression were not measured in H-Ras-siRNA transfected cells.

\section{DISCUSSION}

We have previously shown that H-Ras is activated in the retina and its microvasculature in animal models of diabetic retinopathy, and therapies that prevent accelerated apoptosis of retinal capillary cells and the development of diabetic retinopathy in rats, also inhibit activation of retinal H-Ras and Raf-1 [4,5,14-17], suggesting a major role of this G-protein in the development of diabetic retinopathy. Furthermore, regulation of H-Ras by genetic or by pharmacological means in retinal endothelial cells ameliorates glucose-induced apoptosis, a phenomenon that is considered to precede the development of histopathology [18-21]. Here we demonstrate that the activation of retinal $\mathrm{H}$-Ras in diabetes is mediated via its translocation to the plasma membrane, and administration of simvastatin, which inhibits activation of $\mathrm{H}-$ Ras, also ameliorates its translocation to the membrane. In support, our data from BRECs show that high glucose increases H-Ras expression in the membrane, which can be prevented by the H-Ras-siRNA. These studies clearly elucidate that the translocation of H-Ras to the membrane is a possible mechanism by which it contributes to the development of diabetic retinopathy.

H-Ras exists in two inter-convertible forms-the cytosolic form is GDP-bound and inactive, and the membrane form is GTP-bound and active. Guanine nucleotide exchange factors promote dissociation of GDP from the inactive Ras-GDP complex allowing Ras proteins to bind GTP [3]. The post-translational modifications of Ras make it more hydrophobic facilitating in their translocation from the cytosol to the membrane [3]. In vascular endothelial cells Ras has been shown to translocate to the membrane by oxidized low-density lipoprotein [22], and oxidized low-density lipoprotein are implicated in the development of diabetic retinopathy via increasing apoptosis of retinal capillary cells [23]. Here we show that diabetes increases the membrane expression of H-Ras in the retina. Similar phenomenon is observed in retinal microvascular cells, the cells that are the target of histopathology associated with diabetic retinopathy, suggesting that the translocation of Ras to the membrane is one of the important steps in activating its mediated signaling pathway resulting in accelerated apoptosis of retinal capillary cells.

GTP-Ras interacts with Raf-1 resulting in its translocation to the plasma membrane, and Raf-1 acts as a key effector protein of H-Ras function. Activated Raf subsequently phosphorylates mitogen-activated protein kinase kinase 1/2 -MEK1/2 and they phosphorylate ERK1 and ERK2 [1]. Our previous studies have shown that $\mathrm{H}$-Ras is activated in the retina and its microvasculature in animal models of diabetic retinopathy, and increased apoptosis of retinal capillary cells is, in part, via activation of H-Ras-Raf-1 pathway. Raf-1 kinase inhibitors prevent BRECs from undergoing apoptosis in high glucose conditions, and therapies that prevent apoptosis of retinal capillary cells and the development of diabetic retinopathy in rats also inhibit retinal H-Ras and Raf-1 [4,5,14]. Here we show that the relative expression of Raf- 1 is also increased in the membranes of retina and its capillary cells suggesting that the membrane translocation is an important step in activation of H-Ras-Raf-1 mediated cascade. In support, others have shown that the translocation of Raf-1 to the plasma membrane, which is dependent on the generation of phosphatidic acid, is one of the required steps for Raf activation $[6,7]$. 
Statins, the inhibitors of 3-hydroxy-3-methylglutaryl CoA reductase, are postulated to inhibit $\mathrm{H}$-Ras activation via Ras farnesylation-associated mechanism, block membrane localization of Ras, and inhibit Ras signaling cascade [8]. Simvastatin is shown to inhibit the metabolic abnormalities associated with the development of diabetic retinopathy, including leukocyteendothelial cell interactions, blood retinal barrier breakdown and ICAM-1 expression in both, animal models of diabetic retinopathy and isolated retinal cells [24]. Beneficial effect of lowdose of simvastatin on ischemic retinopathy is linked to angiogenic repair and reduction of ischemia, thereby preventing pathological neovascularization [25]. We show that simvastatin ameliorates translocation of retinal H-Ras to the membrane, and inhibits its activation. In addition, simvastatin also inhibits signaling steps that are downstream of H-Ras, including Raf- 1 and activation of NF- $k$ B. Similar results are obtained from retinal endothelial cells transfected with H-Ras-siRNA. Thus, these data clearly elucidate that the membrane translocation of H-Ras is critical in the activation of H-Ras mediated signaling cascade, and inhibition of membrane translocation is one of the possible mechanism via which simvastatin has potential to inhibit the development of diabetic retinopathy.

H-Ras and its downstream signal transduction cascades are considered to play an important role in the activation of NF- $k \mathrm{~B}$ and its dependent reporter genes [26]. Overexpression of constitutionally active H-Ras further activates NF- $k$ B in BRECs in high glucose conditions [5]. In the pathogenesis of diabetic retinopathy, activation of retinal NF- $k$ B is observed early [27], and it continues to be active at duration when the histopathology is developing in rat retina [18]. NF- $k$ B, via activating nitric oxide synthase, increases NO levels $[18,19]$, and both, NF$k \mathrm{~B}$ and $\mathrm{NO}$ are shown to increase the apoptosis of retinal capillary cells. Here we show that simvastatin administration to diabetic rats prevents activation of retinal NF- $k \mathrm{~B}$ and NO. This is consistent with the published data showing beneficial effect of simvastatin on NF- $k \mathrm{~B}$ activation [28], and suggests that membrane translocation of H-Ras, via activating NF- $k \mathrm{~B}$, culminates in cell death.

In support of our in vivo data, our in vitro data show that the transfection of BRECs with HRas-siRNA, in addition to preventing membrane accumulation of H-Ras induced by high glucose, also inhibits apoptosis of capillary cells. Accelerated apoptosis of retinal capillary cells is shown to precede the appearance of any histopathology changes characteristic of diabetic retinopathy $[22,23]$. Thus, this directly correlates increased membrane translocation of H-Ras to the development of diabetic retinopathy, and suggests that H-Ras, when translocated to the membrane, becomes pro-apoptotic.

In summary, our study using both in vivo and in vitro models of diabetic retinopathy shows that one of the possible mechanisms by which $\mathrm{H}$-Ras contributes to the development of diabetic retinopathy is by its translocation from cytosol to the membrane, this activates H-Ras-Raf-1 signaling cascade and accelerates the apoptosis of retinal cells. Therapies to prevent translocation of H-Ras are expected to have significant beneficial effects in inhibiting the development of diabetic retinopathy, a blinding complication feared by most diabetic patients.

\section{ACKNOWLEDGEMENTS}

This work was supported by grants from the National Institutes of Health, Juvenile Diabetes Research Foundation, the Thomas Foundation, and Research to Prevent Blindness.

\section{REFERENCES}

1. Schubbert S, Bollag G, Shannon K K. Deregulated Ras signaling in developmental disorders: new tricks for an old dog. Curr Opin Genet Dev 2007;17:15-22. [PubMed: 17208427]

2. Esteban LM, Vicario-Abejon C, Fernandez-Salguero P, Fernandez-Medarde A, Swaminathan N, Yienger K, Lopez E, Malumbres M, McKay R, Ward JM, Pellicer A, Santos E. Targeted genomic 
disruption of H-Ras and N-Ras, individually or in combination, reveals the dispensability of both loci for mouse growth and development. Mol Cell Biol 2001;21:1444-1452. [PubMed: 11238881]

3. Stephens E, Thureen PJ, Goalstone ML, Anderson MS, Leitner JW, Hay WW, Draznin B. Fetal hyperinsulinemia increases farnesylation of p21 Ras in fetal tissues. Am J Physiol Endocrinol Metab 2001;281:E217-E223. [PubMed: 11440896]

4. Kowluru RA, Kowluru A, Chakrabarti S, Khan Z. Potential contributory role of H-Ras, a small Gprotein, in the development of retinopathy in diabetic rats. Diabetes 2004;53:775-783. [PubMed: 14988264]

5. Kowluru RA, Kowluru A, Kanwar M. Small molecular weight G-protein, H-Ras, and retinal endothelial cell apoptosis in diabetes. Mol Cell Biochem 2007;296:69-76. [PubMed: 16924412]

6. Goetz CA, O'Neil JJ, Farrar MA. Membrane localization, oligomerization, and phosphorylation are required for optimal raf activation. J Biol Chem 2003;278:51184-51189. [PubMed: 14530258]

7. Kraft CA, Garrido JL, Fluharty E, Leiva-Vega L, Romero G. Role of phosphatidic acid in the coupling of the ERK cascade. J Biol Chem 2008;283:36636-36645. [PubMed: 18952605]

8. Indolfi C, Lorenzo ED, Perrino C, Stingone AM, Curcio A, Torella D, Cittadini A, Cardone L, Coppola C, Cavuto L, Arcucci O, Sacca L, Avvedimento EV, Chiariello M. Hydroxymethylglutaryl Coenzyme A reductase inhibitor simvastatin prevents cardiac hypertrophy induced by pressure overload and inhibits p21ras activation. Circulation 2002;106:2118-2124. [PubMed: 12379583]

9. Kanwar M, Kowluru RA. Role of glyceraldehyde 3-phosphate dehydrogenase in the development and progression of diabetic retinopathy. Diabetes 2009;58:227-234. [PubMed: 18852331]

10. Kowluru RA, Kanwar M. Effect of curcumin on retinal oxidative stress and inflammation in diabetes. Nutr Metab. (Lond) 2007;4:1-8. [PubMed: 17204161]

11. Kowluru RA, Odenbach S. Role of interleukin-1beta in the pathogenesis of diabetic retinopathy. British J Ophthalmol 2004;88:1343-1347.

12. Kowluru RA, Abbas SN. Diabetes-induced mitochondrial dysfunction in the retina. Inves Ophthalmol Vis Sci 2003;44:5327-5334.

13. Kowluru RA, Koppolu P. Diabetes-induced activation of caspase-3 in retina: Effect of antioxidant therapy. Free Radic Res 2002;36:993-999. [PubMed: 12448825]

14. Kowluru RA, Odenbach S. Effect of long-term administration of alpha lipoic acid on retinal capillary cell death and the development of retinopathy in diabetic rats. Diabetes 2004;53:3233-3238. [PubMed: 15561955]

15. Kowluru V, Kowluru RA. Increased oxidative stress in diabetes regulates activation of a small molecular weight G-protein, H-Ras, in the retina. Mol Vis 2007;13:602-610. [PubMed: 17515880]

16. Kanwar M, Chan PS, Kern TS, Kowluru RA. Oxidative damage in the retinal mitochondria of diabetic mice: possible protection by superoxide dismutase. Invest Ophthalmol Vis Sci 2007;48:3805-3811. [PubMed: 17652755]

17. Kanwar M, Kowluru RA. Diabetes regulates small molecular weight G-protein, H-Ras, in the microvasculature of the retina: Implication in the development of retinopathy. Microvascular Research 2008;76:189-193. [PubMed: 18514235]

18. Kowluru RA, Koppolu P, Chakrabarti S, Chen S. Diabetes-induced activation of nuclear transcriptional factor in the retina, and its inhibition by antioxidants. Free Radic Research 2003;37:1169-1180.

19. Kowluru RA. Effect of re-institution of good glycemic control on retinal oxidative stress and nitrative stress in diabetic rats. Diabetes 2003;52:818-823. [PubMed: 12606525]

20. Mizutani M, Kern TS, Lorenzi M. Accelerated death of retinal microvascular cells in human and experimental diabetic retinopathy. J Clin Invest 1996;97:2883-2890. [PubMed: 8675702]

21. Kern TS, Tang J, Mizutani M, Kowluru R, Nagaraj R, Lorenzi M. Response of capillary cell death to aminoguanidine predicts the development of retinopathy: Comparison of diabetes and galactosemia. Invest Ophthalmol Vis Sci 2000;41:3972-3978. [PubMed: 11053301]

22. Sangle GV, Zhao R, Shen GX. Transmembrane signaling pathway mediates oxidized low-density lipoprotein-induced expression of plasminogen activator inhibitor-1 in vascular endothelial cells. Am J Physiol Endocrinol Metab 2008;295:E1243-E1254. [PubMed: 18796547] 
23. Zhang S, WangJ J, Dashti A, Wilson K, Zou MH, Szweda L, Ma JX, Lyons TJ. Pigment epitheliumderived factor (PEDF) mitigates inflammation and oxidative stress in retinal pericytes exposed to oxidized-LDL. J Mol Endocrinol 2008;41:135-143. [PubMed: 18586837]

24. Al-Shabrawey M, Bartoli M, El-Remessy AB, Ma G, Matragoon S, Lemtalsi T, Caldwell RW, Caldwell RW RA. Role of NADPH oxidase and Stat3 in statin-mediated protection against diabetic retinopathy. Invest Ophthalmol Vis Sci 2008;49:3231-3238. [PubMed: 18378570]

25. Medina RJ, O'Neill CL, Devine AB, Gardiner TA, Stitt AW. The pleiotropic effects of simvastatin on retinal microvascular endothelium has important implications for ischaemic retinopathies. PLos ONE 2008;3:e2584. [PubMed: 18612412]

26. Takada Y, Khuri FR, Aggarwal BB. Protein farnesyltransferase inhibitor (SCH 66336) abolishes NFkappaB activation induced by various carcinogens and inflammatory stimuli leading to suppression of NF-kappaB-regulated gene expression and up-regulation of apoptosis. J Biol Chem 2004;279:26287-26299. [PubMed: 15090542]

27. Joussen AM, Huang S, Poulaki V, Camphausen K, Beecken WD, Kirchhof B, Adamis AP. In vivo retinal gene expression in early diabetes. Invest Ophthalmol Vis Sci 2001;42:3047-3057. [PubMed: 11687554]

28. Dichtl W, Dulak J, Frick M, Alber HF, Schwarzacher SP, Ares MP, Nilsson J, Pachinger O, Weidinger F. HMG-CoA reductase inhibitors regulate inflammatory transcription factors in human endothelial and vascular smooth muscle cells. Arterioscler Thromb Vasc Biol 2003;23:58-63. [PubMed: 12524225] 


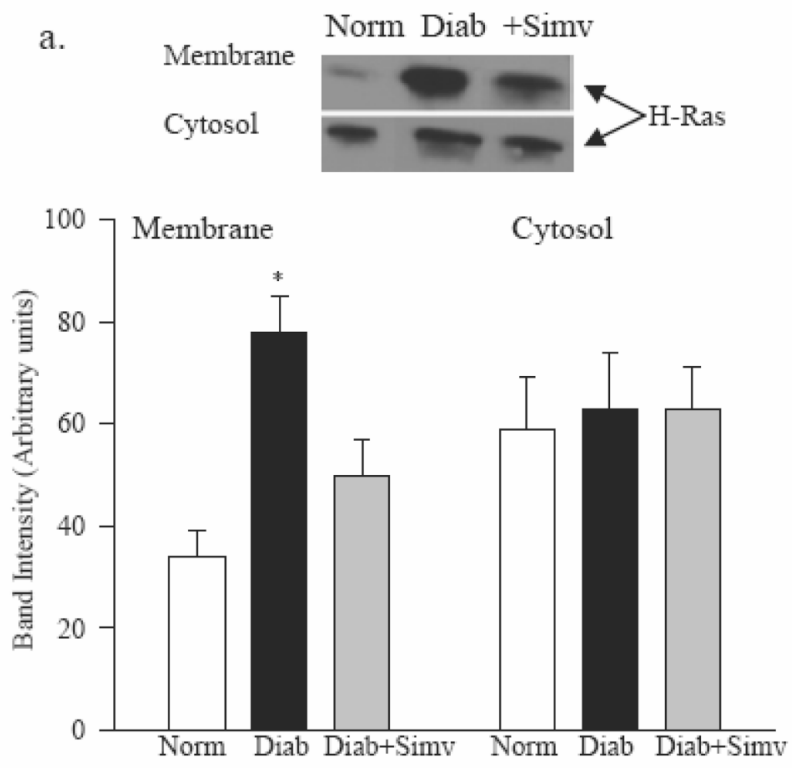

b.

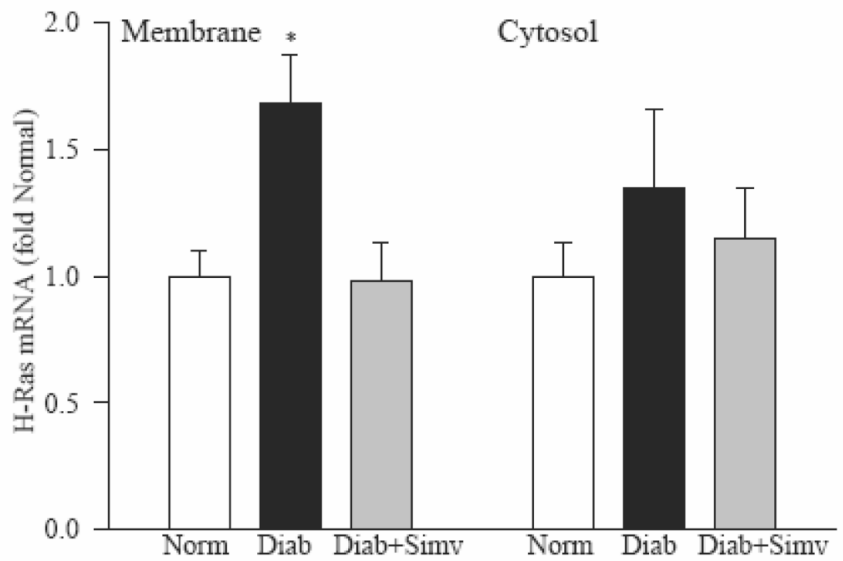

c.
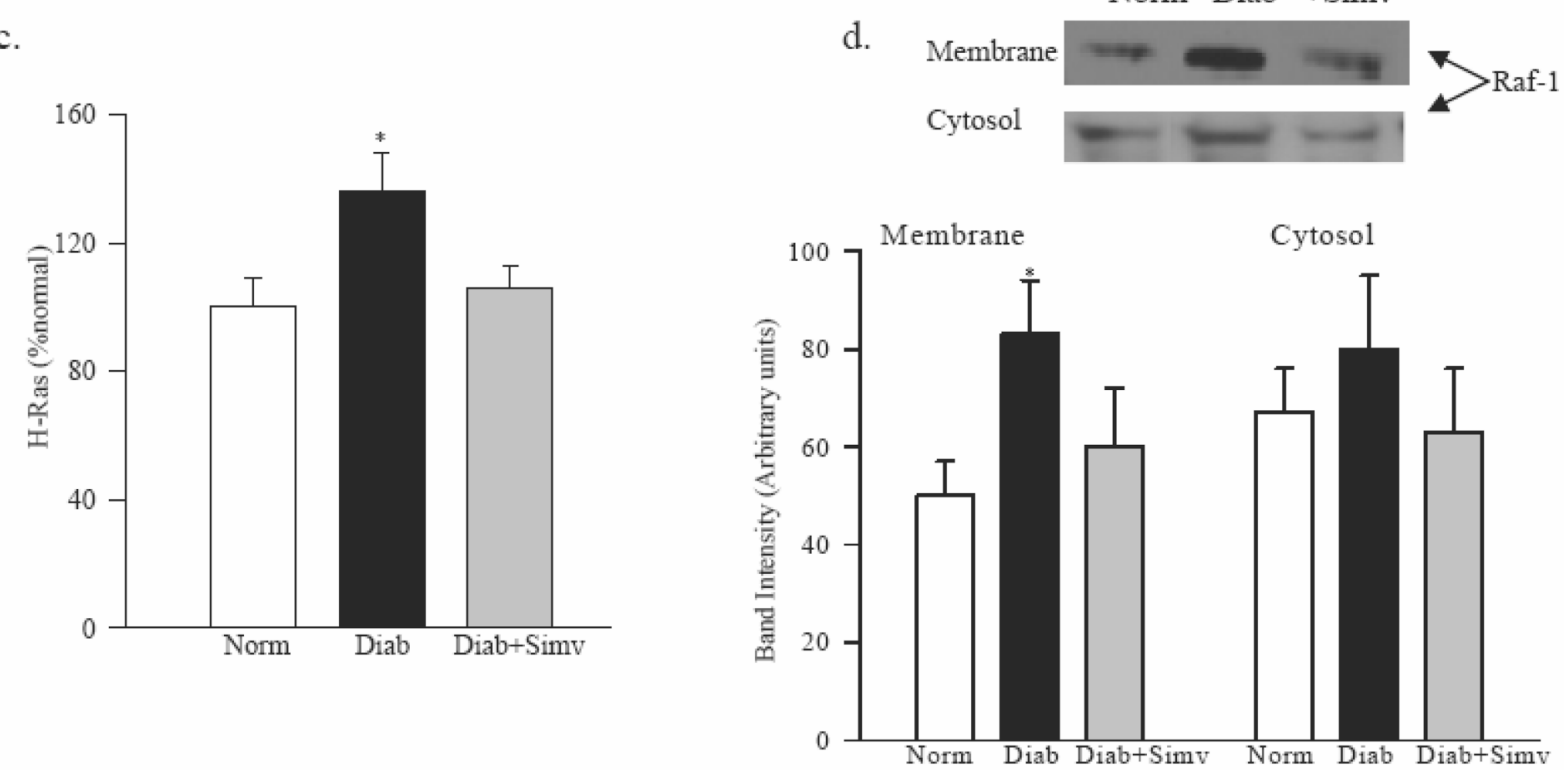

Figure 1. Diabetes translocates retinal H-Ras and Raf-1 from cytosol to the membrane Membrane and cytosol fractions were prepared from retina of rats diabetic for 2 months receiving diets supplemented with or without simvastatin. (a) Protein expression was quantified by western blot using H-Ras antibody, and $\beta$-actin as a loading protein. (b) Gene expressions of H-Ras and Raf-1were quantified by real-time PCR using Taqman custom PCR primers. Data were normalized with B2M mRNA and the fold change in gene expression relative to normal was calculated using the ddCt method. (c) Ras activation was quantified by Raf-1 binding assay kit. (d) Proteins expression of Raf-1 was determined by western blot technique using Raf- 1 antibody and $\beta$-actin as house-keeping protein. The expression of the protein band was quantified using UN-Scan-It Gel digitizing software. Each measurement was made in 
duplicate in 5-7 rats in each group, and are represented as mean $\pm \mathrm{SD}$. ${ }^{*} \mathrm{P}<0.05$ compared to normal. 
a. b.

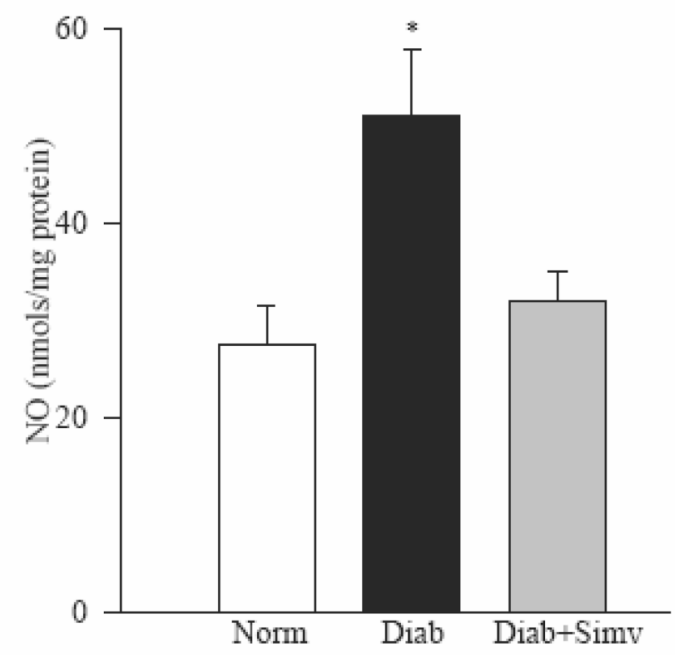

Figure 2. Simvastatin inhibits diabetes-induced activation of retinal NF- $k$ B and decreases NO levels (a) NF- $k$ B activation was determined in the retina by ELISA kit. (b) Nitrite production was quantified by Greiss reagent. Values are represented as mean \pm SD of 6-7 rats in each group with each measurement made in duplicate. Values obtained from normal rat retina are considered as $100 \%$. $* \mathrm{P}<0.05$ compared to normal. 
a.

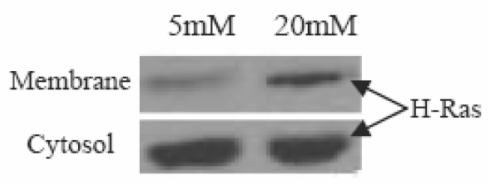

b.

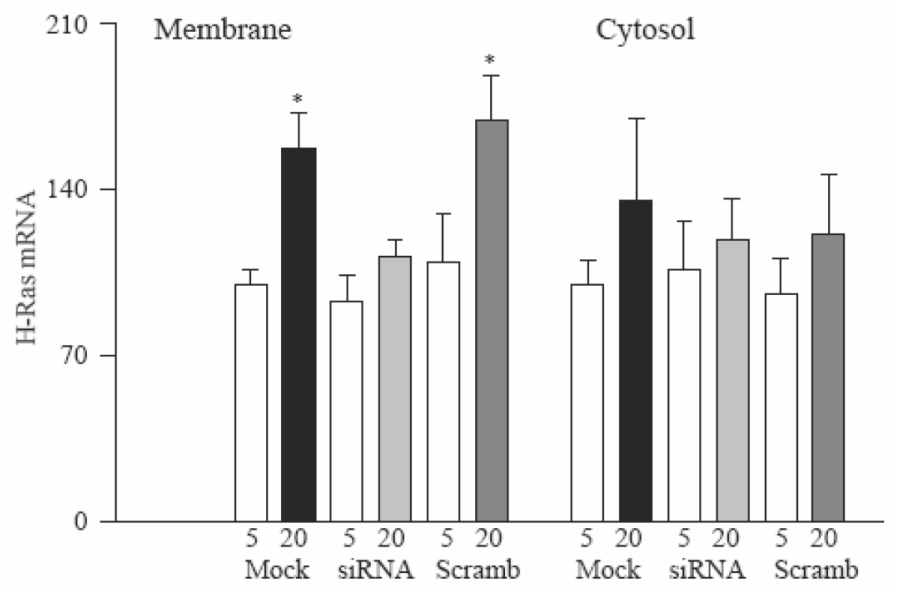

c.

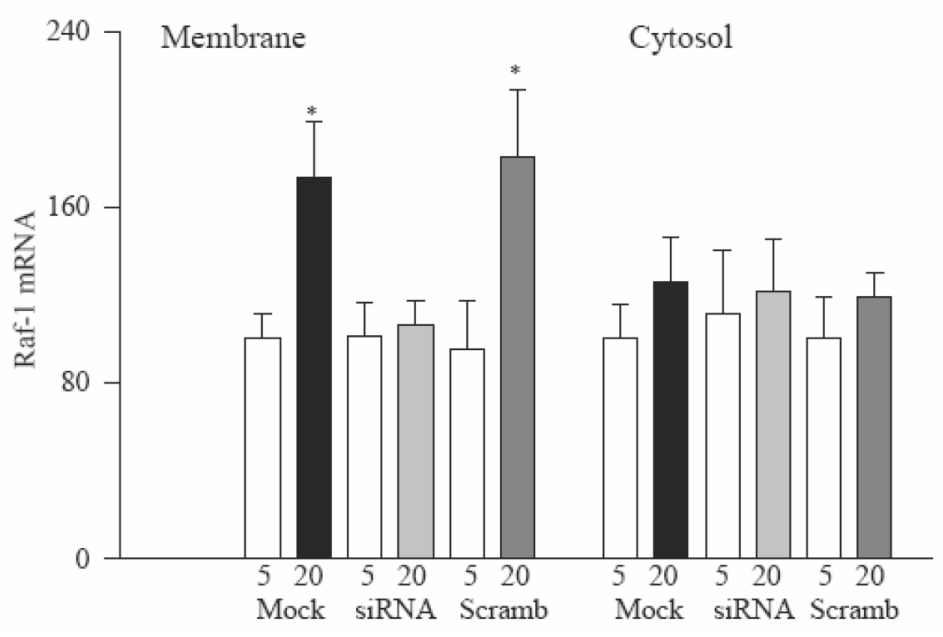

Figure 3. Glucose facilitates translocation of $H$-Ras from cytsosol to the membrane in retinal endothelial cells

(a) Membrane and cytosol fractions were isolated by centrifugation from BRECs incubated in $5 \mathrm{mM}$ or $20 \mathrm{mM}$ glucose. H-Ras protein expression was determined by western blot. (b) BRECs were transfected with H-Ras-siRNA or scrambled-siRNA, followed by incubation in 5mM or $20 \mathrm{mM}$ glucose for 4 days. Cells treated with the siRNA transfection reagent served as controls (Mock). H-Ras mRNA was measured by conventional PCR. Values are mean \pm SD of at least 3 experiments with each measurement made in duplicate. Values obtained from the Mock cells incubated in $5 \mathrm{mM}$ glucose are considered as $100 \%$. $* \mathrm{P}<0.05$ compared to Mock cells in $5 \mathrm{mM}$ 
glucose. $5=5 \mathrm{mM}$ glucose, $20=20 \mathrm{mM}$ glucose, siRNA=H-Ras-siRNA transfected cells, Scramb $=$ Scrambled siRNA transfected cells 
a

c. b.

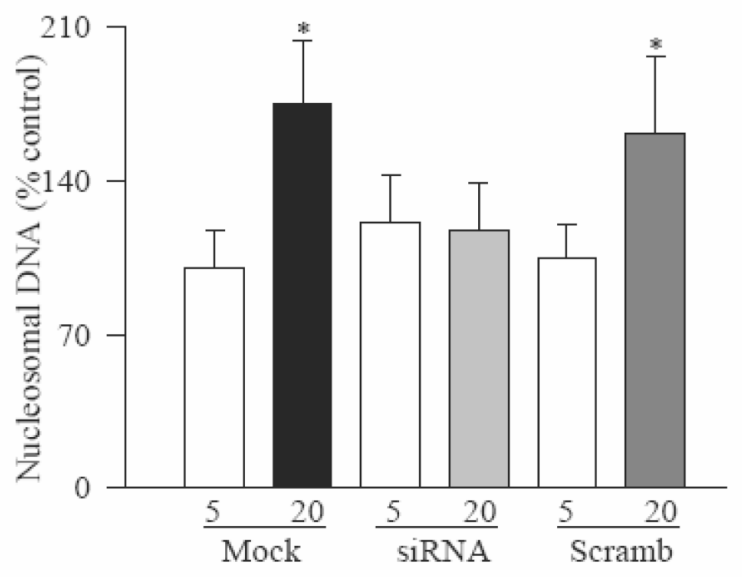

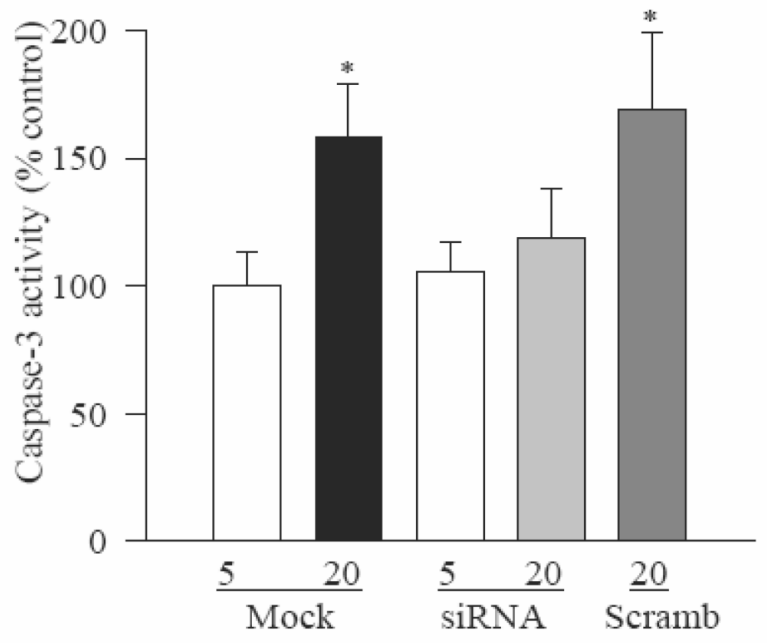

Figure 4. H-Ras siRNA ameliorates glucose-induced increase in apoptosis Endothelial cells transfected with H-Ras-siRNA or scrambled siRNA were incubated in 5mM or 20mM glucose for 4 days. (a) NO was quantified by Greiss reagent, (b) apoptosis by ELISA, and (c) caspase- 3 activity by quantifying the cleavage of fluoregenic substrate. Each measurement was made in duplicate in 4 or more different cell preparations. $* \mathrm{P}<0.05$ compared to Mock cells in $5 \mathrm{mM}$ glucose. 